\title{
ANALISIS PERAWATAN MESIN BUBUT CY-L1640G DENGAN METODE RELIABILITY CENTERED MAINTENANCE (RCM) DI PT. POL YMINDO PERMATA
}

\author{
Agus Syahabuddin \\ Dosen Fakultas Teknik Prodi Teknik Industri Universitas Pamulang \\ Dosen01863@unpam.ac.id
}

\begin{abstract}
ABSTRAK
Persaingan industri yang semakin ketat menuntut setiap perusahaan terus memperbaiki aktivitas operasional lebih optimal. Penelitian ini bertujuan untuk menentukan tindakan perawatan optimal dan menentukan interval waktu perawatan pada Mesin Bubut CY-L1640G pada departemen Maintenance di PT. Polymindo Permata, dimana masih banyak kegiatan perawatan korektif disebabkan kerusakan mesin. Agar tujuan tercapai penulis melakukan analisis secara detail menggunakan metode Reliability Centered Maintenance (RCM), dengan aplikasi awal mengetahui fungsi serta kerusakan yang dapat terjadi pada suatu sistem, mulai dari sub-sistem sampai pada level komponen. Tabel FMEA untuk penentuan komponen kritis, analisa Intermediate Decision Tree (IDT) untuk mengetahui dampak kegagalan baik langsung maupun tidak langsung, kemudian analisis Logic Tree Analysis (LTA) untuk menentukan tugas perawatan yang optimal. Hasil yang didapat adalah pemecahan masalah dimana perusahaan harus melakukan interval perawatan pada komponen Electric System dalam rentang interval 255.07 jam atau 32 hari kerja. Untuk mengetahui tingkat kerusakan komponen dengan melakukan tindakan Condition Monitoring, untuk mengatasi kegagalan yang tidak dapat diprediksi dengan melakukan tindakan Corrective Maintenance dan untuk mengatasi kegagalan yang dipengaruhi usia komponen dengan melakukan tindakan penggantian yang terjadwal.
\end{abstract}

Kata Kunci: Maintenance, RCM, FMEA, IDT, LTA.

\section{PENDAHULUAN}

\section{A. Latar Belakang}

Salah satu pendukung kelancaran aktivitas operasional adalah kondisi mesin harus selalu siap digunakan, maka diperlukan sistem perawatan yang baik. Pada dasarnya ada dua kegiatan pokok perawatan yaitu preventif dan korektif. Perawatan preventif mesin bubut di PT. Polymindo Permata masih belum optimal, dibuktikan dengan masih banyak perawatan korektif oleh departemen Maintenance.

Data historis perbaikan 4 unit mesin bubut CY-L1640G diambil selama 2 tahun terakhir yaitu mulai dari Januari 2017 sampai dengan Desember 2018, yang meliputi data perawatan korektif dan data perawatan preventif. Berikut grafik downtime perawatan mesin bubut $\mathrm{CY}$ L1640G di PT. Polymindo Permata ditunjukan pada Tabel 1.1.

Tabel 1.1 Downtime Kerusakan Mesin

\begin{tabular}{|c|c|c|c|r|}
\hline No & Mesin & Downtime & $\begin{array}{c}\% \\
\text { Downtime }\end{array}$ & $\begin{array}{c}\% \\
\text { Downtime } \\
\text { Komulatif }\end{array}$ \\
\hline 1 & No. 3 & 15.92 & 32.43 & 32.43 \\
\hline 2 & No. 1 & 14.06 & 24.18 & 56.61 \\
\hline 3 & No. 2 & 10.48 & 36.72 & 93.33 \\
\hline 4 & No. 4 & 2.89 & 6.67 & 100.00 \\
\hline \multicolumn{2}{|c|}{ Total } & 27.43 & $100 \%$ & \multicolumn{2}{c}{} \\
\cline { 1 - 3 } & &
\end{tabular}

(Sumber PT. Polymindo Permata, 2019)

Penelitian ini bertujuan untuk menentukan tindakan perawatan yang optimal dan menentukan interval waktu perawatan pada Mesin Bubut CY-L1640G dengan metode Reliability Centered Maintenance (RCM).

\section{B. Perumusan Masalah}

Berdasar pada masalah penelitian yaitu tentang perencanaan perawatan, selanjutnya dirumuskan pertanyaan penelitian sebagai berikut: 
1. Bagaimana menentukan tindakan perawatan yang optimal pada Mesin Bubut CYL1640G di PT. Polymindo Permata memakai pendekatan metode Reliability Centered Maintenance (RCM)?

2. Bagaimana menentukan interval waktu perawatan memakai pendekatan metode Reliability Centered Maintenance (RCM) pada Mesin Bubut CY-L1640G di PT. Polymindo Permata?

\section{Pembatasan Masalah}

Agar penelitian tidak melebar dan menyimpang dari tujuan awal, maka penulis memberikan beberapa batasan, antara lain:

1. Aspek instalasi dan biaya kegiatan perawatan tidak menjadi parameter dalam pembahasan.

2. Penelitian dilakukan terhadap mesin bubut CY-L1640G dalam lingkup Departemen Maintenance.

3. Data historis yang diambil adalah mulai dari Januari 2017 sampai Desember 2018.

\section{Tujuan Penelitian}

Tujuan dari penelitian ini adalah:

1. Menentukan tindakan perawatan optimal pada Mesin Bubut CY-L1640G di PT. Polymindo Permata memakai pendekatan metode Reliability Centered Maintenance (RCM).

2. Menentukan interval waktu perawatan memakai pendekatan metode Reliability Centered Maintenance (RCM) pada Mesin Bubut CY-L1640G di PT. Polymindo Permata.

\section{DASAR TEORI}

\section{A. Reliability Centered Maintenance (RCM)}

Menurut Kurniawan (2013) Reliability Centered Maintenance (RCM) merupakan metode perawatan dengan memanfaatkan informasi terkait dengan keandalan fasilitas untuk mendapatkan strategi perawatan fasilitas yang efektif dan efisien serta mudah dilakukan.

Menurut Pranoto (2015) Reliability Centered Maintenance (RCM) merupakan metode yang digunakan untuk penentuan kebutuhan perawatan atas aset fisik dalam konteks operasinya.

Menurut Siswanti (2017) RCM adalah teknik untuk mengembangkan program preventive maintenance. $\mathrm{Hal}$ tersebut didasarkan pada asumsi bahwa keandalan yang melekat pada peralatan adalah fungsi dari desain dan pembangunan kualitas.

Menurut Smith (1993) dalam Aufar et al. (2014) Metode RCM bertujuan untuk mengoptimalkan preventive maintenance dengan prinsip:

1. Mempertahankan fungsi sistem.

2. Mengidentifikasi moda kegagalan.

3. Memprioritaskan kebutuhan fungsi melalui mode kegagalan.

4. Memilih tindakan preventive maintenance yang efektif dan dapat diterapkan.

\section{B. Langkah Implementasi RCM}

Menurut Kurniawan (2013) secara umum ada beberapa langkah implementasi RCM, antara lain:

1. Pembuatan Hirarki Fungsi dari Sistem Peralatan dengan mengidentifikasi sistem dan sub sistem secara fungsional.

2. Analisa Kegagalan Fungsi yaitu kegiatan deskripsi tiap sistem sub sistem, komponen serta identifikasi semua fungsi dan interface dengan sistem atau sub sistem yang lain dan identifikasi semua kegagalan fungsional.

3. Penentuan Significant Item dengan indeks kekritisan.

4. Failure Mode and Effect Analysis (FMEA) untuk analisis kegagalan dengan fokus pada analisis kualitatif dan identifikasi dampak moda kegagalan dan cara deteksi moda kegagalan tersebut.

Rumus dalam perhitungan FMEA yaitu:

$$
R P N=S \times O \times D \text {. }
$$

Dimana:

$$
\begin{array}{ll}
\mathrm{S} & =\text { Severity } \\
\mathrm{O} & =\text { Occurance } \\
\mathrm{D} & =\text { Detection }
\end{array}
$$

Nilai RPN menunjukan keseriusan potensial failure, semakin tinggi RPN menunjukan semakin bermasalah.

5. Intermediate Decision Tree (IDT)

Menurut Sandtrove (1990) dalam Kurniawan (2013), IDT adalah analisis untuk mengetahui kegagalan yang tampak atau tersembunyi, kedalam 4 kategori tersebut antara lain:
a. Kategori A (berpengaruh terhadap keselamatan).
b. Kategori B (berpengaruh terhadap produksi).
c. Kategori C (berpengaruh terhadap non- produksi)


d. Kategori D (mode kegagalan yang tersembunyi).

Apabila jawaban pertanyaan mengarahkan moda kegagalan pada kategori D, maka analisis dilanjutkan kembali apakah item tersebut masuk dalam kategori D/A, D/B atau $\mathrm{D} / \mathrm{C}$.

6. Logic Tree Analysis (LTA)

Tujuan LTA adalah mengklasifikasikan failure mode kedalam beberapa kategori agar dapat dipilih antara tugas perawatan yang applicable dan effective. Pemilihan tugas perawatan tersebut menurut Sandtrove (1990) dalam Kurniawan (2013) antara lain:

a. Pengujian / Inspeksi berkala.

b. Evaluasi hubungan equipment dengan resiko.

c. Scheduled rework.

d. Penggantian terjadwal.

e. Condition monitoring.

f. Pengawasan oleh operator atau pengontrolan sistem.

g. Operasikan sampai mengalami kegagalan.

\section{Kerangka Fikir}

Berdasarkan tinjauan landasan teori dapat disusun kerangka fikir dalam penelitian ini, seperti ditunjukan pada Gambar 2.1.

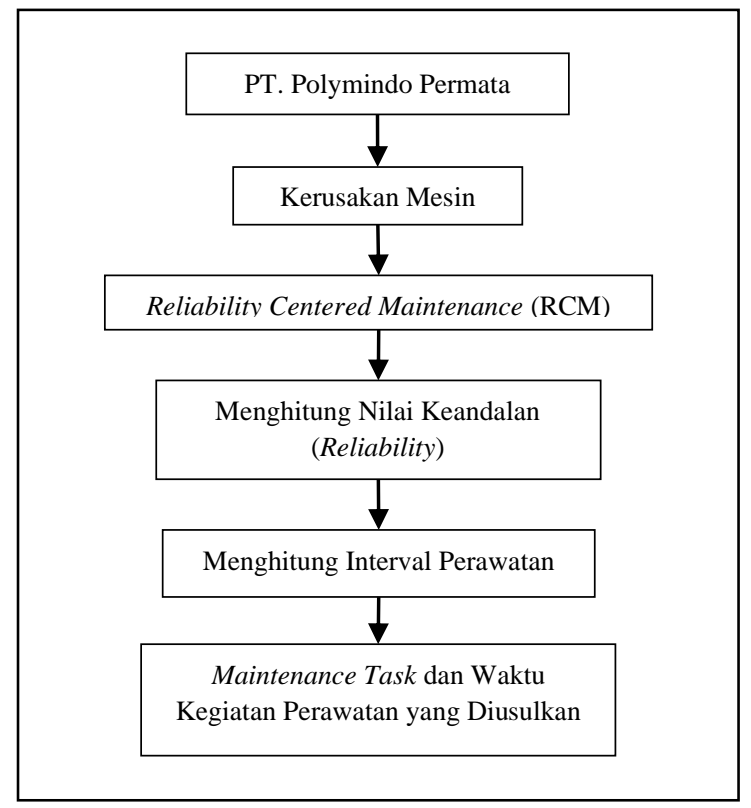

(Sumber Pengolahan Data, 2019)

Gambar 2.1 Kerangka Fikir Penelitian

\section{METODOLOGI PENELITIAN}

\section{A. Jenis Penelitian}

Penelitian menggunakan metode deskriptif analitis yaitu pengumpulan, pengolahan dan penyajian data sesuai fakta dan analisis ilmiah yang hasilnya digunakan untuk pengambilan keputusan dalam rangka pemecahan masalah pada kerusakan mesin bubut.

\section{B. Sumber Data}

Sumber data didapatkan dari internal perusahaan, berupa data primer dan sekunder dari internal perusahaan meliputi:

1. Data Primer.
a. Data umum perusahaan.
b. Data perawatan korektif.
c. Data perawatan preventif.
d. Data jam kerja efektif mesin.

2. Data Sekunder.
a. Studi kepustakaan mengenai manajemen perawatan
b. Disiplin ilmu pengetahuan lain yang mendukung dan berhubungan dengan topik penelitian.

\section{Teknik Pengumpulan Data}

Teknik pengumpulan data yang digunakan antara lain:

1. Teknik observasi.

2. Teknik wawancara.

3. Teknik studi literatur.

4. Teknik dokumentasi.

\section{Metode Analisa Data}

Setelah semua data diperlukan terkumpul, kemudian dilakukan analisis sebagai berikut:

1. Melakukan langkah-langkah implementasi Reliability Centered Maintenance (RCM) terhadap mesin, antara lain:

a. Membuat hirarki fungsi sistem peralatan.

b. Melakukan analisis kegagalan fungsi.

c. Menentukan item yang significant.

d. Membuat analisis Failure Mode and Effect Analysis (FMEA)

e. Membuat analisis Intermediate Decision Tree (IDT)

f. Membuat analisis Logic Tree Analysis (LTA)

2. Menghitung tingkat keandalan (reliability) berdasar pada kemampuan perawatan (maintainability) dan ketersediaan (availability) mesin.

3. Analisis perbandingan antara metode kebijaksanaan perusahaan dengan metode hasil pengolahan data sehingga menghasilkan jadwal perawatan mesin. 
4. Menentukan strategi perencanaan perawatan optimal pada mesin.

5. Membuat kesimpulan dari penelitian yang dilakukan.

6. Memberikan usulan atau saran kepada perusahaan untuk melakukan perbaikan pada departemen Maintenance.

\section{E. Flow Chart}

Flow Chart ditunjukan pada Gambar 3.1.

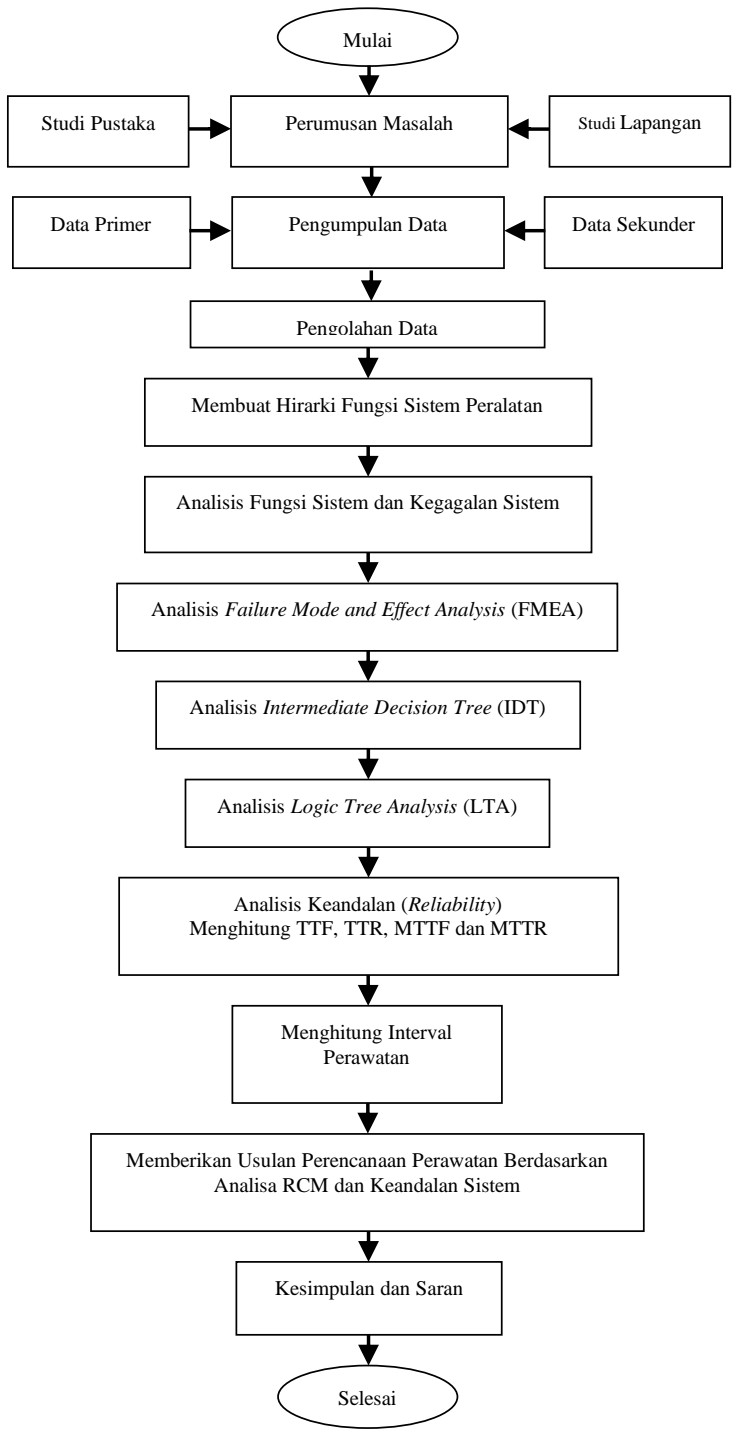

(Sumber Analisa Penulis, 2019)

Gambar 3.1. Flowchart Metodologi Penelitian

\section{HASIL DAN PEMBAHASAN}

\section{A. Hirarki Fungsi Sistem}

Penentuan hirarki fungsi pada mesin bubut CY-L1640G dengan mengelompokan tiap fungsi sistem dan sub sistem sampai level komponen sehingga secara logika akan terkait dalam sistem hirarki. Penentuan hirarki sistem ditunjukan oleh Tabel 4.1.
Tabel 4.1 Hirarki Fungsi Sistem

\begin{tabular}{|c|c|c|}
\hline Sistem & Sub-Sistem & Komponen \\
\hline \multirow{44}{*}{ 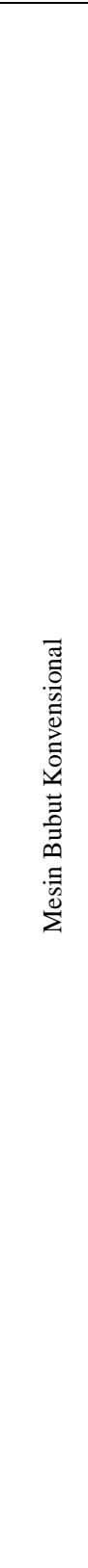 } & \multirow[t]{8}{*}{ Kepala Tetap } & Shaft + Bushing \\
\hline & & V-Belt + Pulley \\
\hline & & Gearbox \\
\hline & & Oil Gearbox \\
\hline & & $\begin{array}{l}\text { Electric System } \\
\text { (Electric Panel) }\end{array}$ \\
\hline & & Bearing \\
\hline & & Bolt and Nut \\
\hline & & Safety \\
\hline & \multirow[t]{5}{*}{ Kepala Lepas } & Shaft + Bushing \\
\hline & & Bolt and Nut \\
\hline & & Safety \\
\hline & & Gear \\
\hline & & Bearing \\
\hline & \multirow[t]{5}{*}{ Alas Mesin } & Pressure \\
\hline & & Oil Circulating \\
\hline & & Hydrolic / Air Hose \\
\hline & & Bolt and Nut \\
\hline & & Safety \\
\hline & \multirow[t]{7}{*}{ Eretan } & Taper \\
\hline & & Shaft + Bushing \\
\hline & & Gear \\
\hline & & $\begin{array}{l}\text { Electric System } \\
\text { (Control Panel) }\end{array}$ \\
\hline & & Bearing \\
\hline & & Gibs, Bolt and Nut \\
\hline & & Safety \\
\hline & \multirow[t]{3}{*}{ Tool Post } & Safety \\
\hline & & Bolt and Nut \\
\hline & & $\begin{array}{l}\text { Insert / Pahat Bubut } \\
\text { (External Component) }\end{array}$ \\
\hline & \multirow[t]{4}{*}{ Poros Pembawa } & Shaft + Bushing \\
\hline & & Gear \\
\hline & & Bearing \\
\hline & & Bolt and Nut \\
\hline & \multirow[t]{4}{*}{ Poros Transportir } & $\begin{array}{l}\text { Shaft (Thread) + } \\
\text { Bushing }\end{array}$ \\
\hline & & Gear \\
\hline & & Bearing \\
\hline & & Bolt and Nut \\
\hline & \multirow[t]{4}{*}{ Tuas } & Gear \\
\hline & & Shaft + Bushing \\
\hline & & Safety \\
\hline & & Bolt and Nut \\
\hline & \multirow[t]{4}{*}{ Cekam/Chuck } & Shaft + Bushing \\
\hline & & Bearing \\
\hline & & Shoe, Bolt and Nut \\
\hline & & Safety \\
\hline
\end{tabular}

(Sumber Pengolahan Data, 2019)

\section{B. Analisa Sistem}

Berdasarkan teori Sandtrove (1990) dalam Kurniawan (2013). Analisa sistem meliputi analisis fungsi sistem dan kegagalan sistem untuk mengetahui fungsi komponen beserta kegagalan yang dapat terjadi, analisis IDT untuk mengetahui kegagalan termasuk yang nampak atau tersembunyi, dan untuk menentukan tugas perawatan dilakukan Analisa LTA.

Tabel 4.2 Analisa Sistem 


\begin{tabular}{|c|c|c|c|c|c|}
\hline \multirow{3}{*}{$\begin{array}{l}\text { Komponen } \\
\text { Sistem }\end{array}$} & \multirow{3}{*}{$\begin{array}{l}\text { Fungsi } \\
\text { Sistem }\end{array}$} & \multirow{3}{*}{$\begin{array}{c}\text { Kegagalan } \\
\text { Sistem }\end{array}$} & \multirow{3}{*}{$\begin{array}{c}\text { IDT } \\
\text { Dampak Kegagalan } \\
\text { (Nampak / } \\
\text { Tersembunyi) }\end{array}$} & \multirow{2}{*}{\multicolumn{2}{|c|}{$\begin{array}{c}\text { LTA } \\
\text { Pemilihan } \\
\text { Maintenance Task }\end{array}$}} \\
\hline & & & & & \\
\hline & & & & $\begin{array}{c}\text { Kate- } \\
\text { gori }\end{array}$ & $\begin{array}{c}\text { Keterang- } \\
\text { an }\end{array}$ \\
\hline \multirow[t]{2}{*}{ Chuck } & \multirow{2}{*}{$\begin{array}{l}\text { Untuk } \\
\text { menjepit } \\
\text { benda kerja }\end{array}$} & $\begin{array}{l}\text { Shoe tidak } \\
\text { center }\end{array}$ & \multirow{2}{*}{$\begin{array}{l}\text { Dampak terasa } \\
\text { langsung dan } \\
\text { berpengarah terhadap } \\
\text { produksi }\end{array}$} & \multirow[t]{2}{*}{ F } & \multirow{2}{*}{$\begin{array}{l}\text { Pengawasan } \\
\text { Oleh } \\
\text { Operator }\end{array}$} \\
\hline & & Shoe macet & & & \\
\hline Taper & $\begin{array}{l}\text { Untuk } \\
\text { pembubutan } \\
\text { tirus }\end{array}$ & \begin{tabular}{|l|}
$\begin{array}{l}\text { Tidak dapat } \\
\text { di-lock }\end{array}$ \\
Gibs longgar \\
Pahat patah
\end{tabular} & $\begin{array}{l}\text { Dampak terasa } \\
\text { langsung dan } \\
\text { berpengaruh terhadap } \\
\text { produksi }\end{array}$ & $\mathrm{F}$ & $\begin{array}{l}\text { Pengawasan } \\
\text { Oleh } \\
\text { Operator }\end{array}$ \\
\hline \multirow[t]{2}{*}{ Pressure } & $\begin{array}{l}\text { Memberi } \\
\text { tekanan pada }\end{array}$ & $\begin{array}{l}\text { Tidak ada } \\
\text { tekanan }\end{array}$ & \multirow{2}{*}{$\begin{array}{l}\text { Dampak terasa } \\
\text { langsung dan } \\
\text { berpengaruh terhadap } \\
\text { produksi }\end{array}$} & \multirow{2}{*}{ E } & \multirow{2}{*}{$\begin{array}{l}\text { Condition } \\
\text { Monitoring }\end{array}$} \\
\hline & $\begin{array}{l}\text { Air Pressure } \\
\text { dan Hydrolic } \\
\text { Pressure }\end{array}$ & \begin{tabular}{|l|} 
Tekanan \\
lemah
\end{tabular} & & & \\
\hline \multirow[t]{3}{*}{$\begin{array}{l}\text { Shaft + } \\
\text { Bushing }\end{array}$} & \multirow{3}{*}{$\begin{array}{l}\text { Shaft } \\
\text { berfungsi } \\
\text { sebagai } \\
\text { poros, } \\
\text { bushing } \\
\text { berfungsi } \\
\text { sebagai } \\
\text { bantalan } \\
\text { shaft }\end{array}$} & Shaff goyang & \multirow{3}{*}{$\begin{array}{l}\text { Dampak terasa } \\
\text { langsung dan } \\
\text { berpengaruh terhadap } \\
\text { produksi }\end{array}$} & c & $\begin{array}{l}\text { Schduled } \\
\text { Rework } \\
\text { Servicing }\end{array}$ \\
\hline & & Bushing aus & & \multirow[b]{2}{*}{ E } & \multirow[b]{2}{*}{$\begin{array}{l}\text { Condition } \\
\text { Monitoring }\end{array}$} \\
\hline & & Bracket rusak & & & \\
\hline Bearing & $\begin{array}{l}\text { Mengurangi } \\
\text { gesekan } \\
\text { antara shaft } \\
\text { dengan } \\
\text { bagian } \\
\text { mesin } \\
\text { laimnya }\end{array}$ & Bearing aus & $\begin{array}{l}\text { Dampak terasa } \\
\text { langsung dan } \\
\text { berpengaruh terhadap } \\
\text { produksi }\end{array}$ & D & $\begin{array}{l}\text { Penggantian } \\
\text { Terjadwal }\end{array}$ \\
\hline \multirow[t]{4}{*}{$\begin{array}{l}\text { V-Belt + } \\
\text { Pulley }\end{array}$} & \multirow{4}{*}{$\begin{array}{l}\text { Berfungsi } \\
\text { sebagai } \\
\text { penyambung } \\
\text { daya dari } \\
\text { motor ke } \\
\text { poros } \\
\text { melalui pully } \\
\text { mengikuti } \\
\text { laju putaran } \\
\text { pada } \\
\text { gearbox }\end{array}$} & \begin{tabular}{|l|} 
Belt pecah \\
\end{tabular} & $\begin{array}{l}\text { Dampak tidak } \\
\text { langsung, tersembunyi } \\
\text { dan berpengaruh } \\
\text { terhadap produksi }\end{array}$ & D & $\begin{array}{l}\text { Penggantian } \\
\text { Terjadwal }\end{array}$ \\
\hline & & Belt kendur & \multirow{3}{*}{$\begin{array}{l}\text { Dampak terasa } \\
\text { langsung dan } \\
\text { berpengaruh terhadap } \\
\text { produksi }\end{array}$} & \multirow[t]{2}{*}{ E } & $\begin{array}{l}\text { Condition } \\
\text { Monitoring }\end{array}$ \\
\hline & & $\begin{array}{l}\text { Belt slip } \\
\text { Pully ans }\end{array}$ & & & \\
\hline & & & & C & $\begin{array}{l}\text { Schduled } \\
\text { Rework } \\
\text { Servicing }\end{array}$ \\
\hline Bolt and Nut & $\begin{array}{l}\text { Sambungan } \\
\text { antar } \\
\text { komponen }\end{array}$ & $\begin{array}{l}\text { Bolt and Nut } \\
\text { kendur }\end{array}$ & $\begin{array}{l}\text { Dampak terasa } \\
\text { langsung dan } \\
\text { berpengaruh terhadap } \\
\text { produksi }\end{array}$ & $\mathrm{F}$ & $\begin{array}{l}\text { Pengawasan } \\
\text { Oleh } \\
\text { Operator }\end{array}$ \\
\hline $\begin{array}{l}\text { Oil } \\
\text { Circulating }\end{array}$ & $\begin{array}{l}\text { Melumasi } \\
\text { mesin dan } \\
\text { benda kerja } \\
\text { agar tidak } \\
\text { panas }\end{array}$ & $\begin{array}{l}\text { Hose mampet } \\
\text { Koneksi hose } \\
\text { lepas }\end{array}$ & $\begin{array}{l}\text { Drouuksi } \\
\text { Dampak terasa } \\
\text { langsung dan } \\
\text { berpengaruh terhadap } \\
\text { produksi }\end{array}$ & $\mathrm{F}$ & $\begin{array}{l}\text { Pengawasan } \\
\text { Oleh } \\
\text { Operator }\end{array}$ \\
\hline Oil Gear box & $\begin{array}{l}\text { Pelumas } \\
\text { pada } \\
\text { gearbox }\end{array}$ & $\begin{array}{l}\text { Kurang } \\
\text { pelumasan } \\
\text { pada part }\end{array}$ & $\begin{array}{l}\text { Dampak terasa } \\
\text { langsung dan } \\
\text { berpengaruh terhadap } \\
\text { produksi }\end{array}$ & $\mathrm{F}$ & $\begin{array}{l}\text { Pengawasan } \\
\text { Oleh } \\
\text { Operator }\end{array}$ \\
\hline \multirow[t]{4}{*}{$\begin{array}{l}\text { Electric } \\
\text { System }\end{array}$} & \multirow[t]{4}{*}{$\begin{array}{l}\text { Motor } \\
\text { penggerak } \\
\text { mesin }\end{array}$} & $\begin{array}{l}\text { Kabel } \\
\text { terkelupas }\end{array}$ & $\begin{array}{l}\text { Dampak tidak } \\
\text { langsung, tersembunyi } \\
\text { dan berpengaruh } \\
\text { terhadap keselamatan }\end{array}$ & E & $\begin{array}{l}\text { Condition } \\
\text { Monitoring }\end{array}$ \\
\hline & & Relay rusak & & & \\
\hline & & $\begin{array}{l}\text { Kontaktor } \\
\text { rusak }\end{array}$ & $\begin{array}{l}\text { langsing, tersembunyi } \\
\text { dan berpengaruh } \\
\text { terhadap produksi }\end{array}$ & B & $\begin{array}{l}\text { No Task } \\
\text { (CM ony) }\end{array}$ \\
\hline & & Kumparan & & D & Penggantian \\
\hline $\begin{array}{l}\text { Hydrolic/ } \\
\text { Air Hose }\end{array}$ & $\begin{array}{l}\text { Memberi } \\
\text { tekanan pada }\end{array}$ & \begin{tabular}{|l} 
5topper break \\
Pompa rusalk
\end{tabular} & $\begin{array}{l}\text { Dampak terasa } \\
\text { langsung dan }\end{array}$ & E & $\begin{array}{l}\text { Terjadwal } \\
\text { Condition } \\
\text { Monitoring }\end{array}$ \\
\hline & oli agar & Filter kotor & berpengaruh terhadap & & Pengawasan \\
\hline & $\begin{array}{l}\text { bergerak } \\
\text { melumasi } \\
\text { mesin }\end{array}$ & $\begin{array}{l}\text { Oli tidak } \\
\text { mengalir }\end{array}$ & & F & $\begin{array}{l}\text { Oleh } \\
\text { Operator }\end{array}$ \\
\hline Gear & $\begin{array}{l}\text { Roda } \\
\text { penggerak }\end{array}$ & Gear aus & $\begin{array}{l}\text { Dampak terasa } \\
\text { langsung dan } \\
\text { berpenganuh terhadap } \\
\text { produlksi }\end{array}$ & c & $\begin{array}{l}\text { Schaduled } \\
\text { Rework } \\
\text { Servicing }\end{array}$ \\
\hline Sajety & $\begin{array}{l}\text { Safety cover } \\
\text { Safety tools } \\
\text { Stopper } \\
\text { Penampang }\end{array}$ & $\begin{array}{l}\text { Stopper rusak } \\
\text { Thread aus }\end{array}$ & $\begin{array}{l}\text { Dampakk terasa } \\
\text { langsung dan } \\
\text { berpengaruh terhadap } \\
\text { produksi }\end{array}$ & & \\
\hline & & $\begin{array}{l}\text { Penampang oli } \\
\text { bocor }\end{array}$ & $\begin{array}{l}\text { Dampak terasa } \\
\text { langsung dan } \\
\text { berpengaruh terhadap } \\
\text { non-produksi }\end{array}$ & F & $\begin{array}{l}\text { Pengawasan } \\
\text { Oleh } \\
\text { Operator }\end{array}$ \\
\hline & & $\begin{array}{l}\text { Gram } \\
\text { mengenai } \\
\text { operator }\end{array}$ & $\begin{array}{l}\text { Dampak terasa } \\
\text { langsung dan } \\
\text { berpengaruh terhadap } \\
\text { safety }\end{array}$ & & \\
\hline
\end{tabular}

(Sumber Pengolahan Data, 2019)

\section{Analisa FMEA}

FMEA mengidentifikasi setiap moda kegagalan yang berpotensi menjadi penyebab kegagalan fungsi pada komponen sistem mesin bubut. Tabel perhitungan FMEA ditunjukan pada Tabel 4.3.

Tabel 4.3. Tabel RPN FMEA

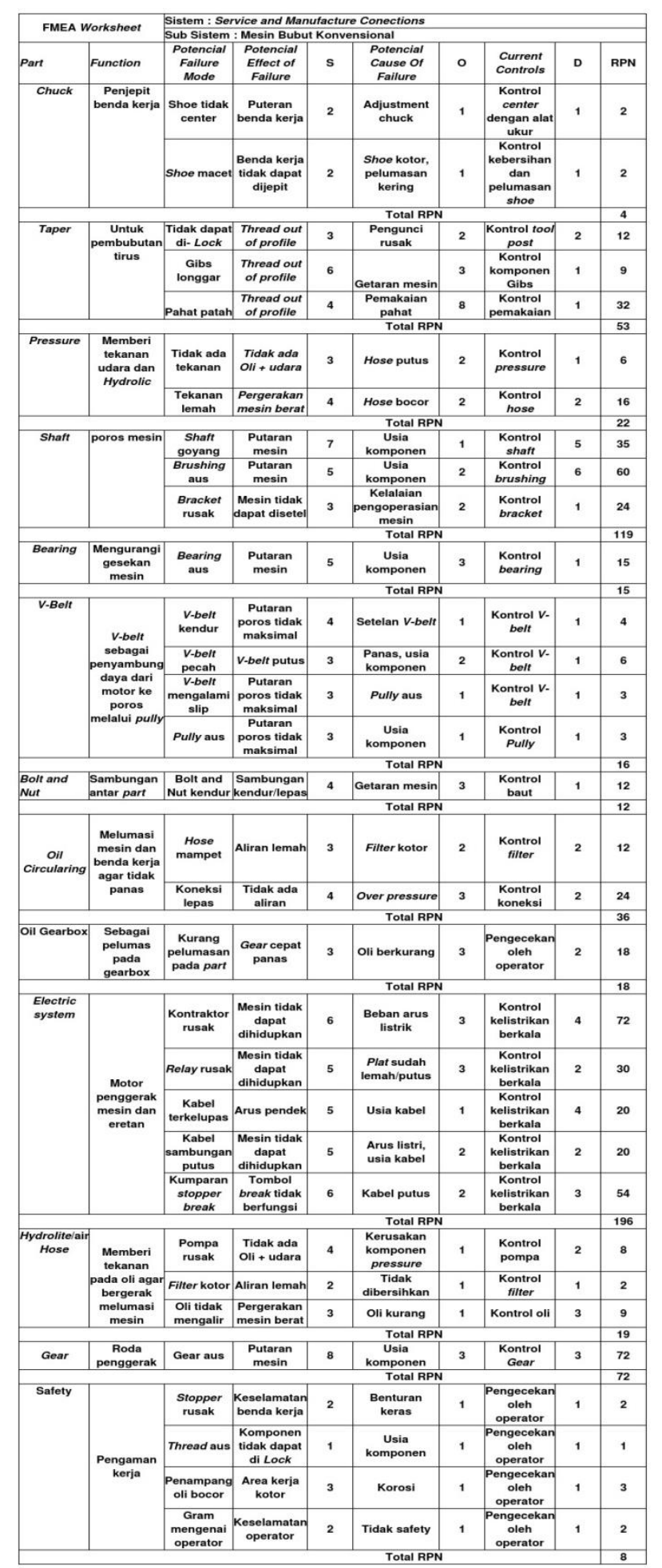

(Sumber Pengolahan Data, 2019)

Dari FMEA diidentifikasi nilai tertinggi pada komponen Electric System sebesar RPN 196, komponen Shaft dengan RPN 119 dan komponen Gear dengan RPN 72.

\section{Analisa Keandalan (Reliability)}

Analisa keandalan mesin bubut CYL1640G diawali dengan menentukan mesin 
kritis, kemudian dilanjutkan dengan mencari komponen kritis, dengan kriteria banyaknya downtime yang terjadi akibat kerusakan.

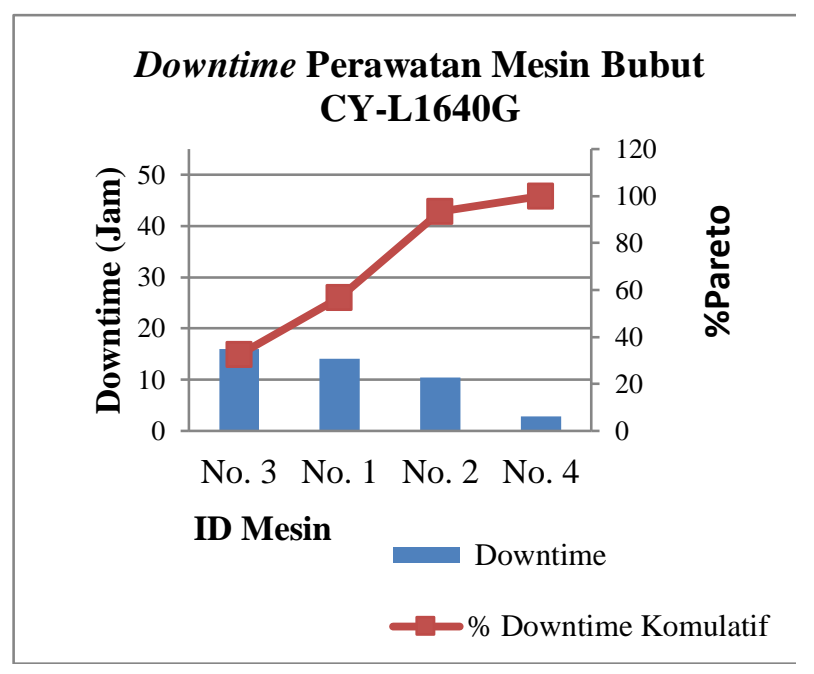

(Sumber PT. Polymindo Permata, 2019)

Gambar 4.1 Downtime Perawatan Mesin Bubut Konvensional

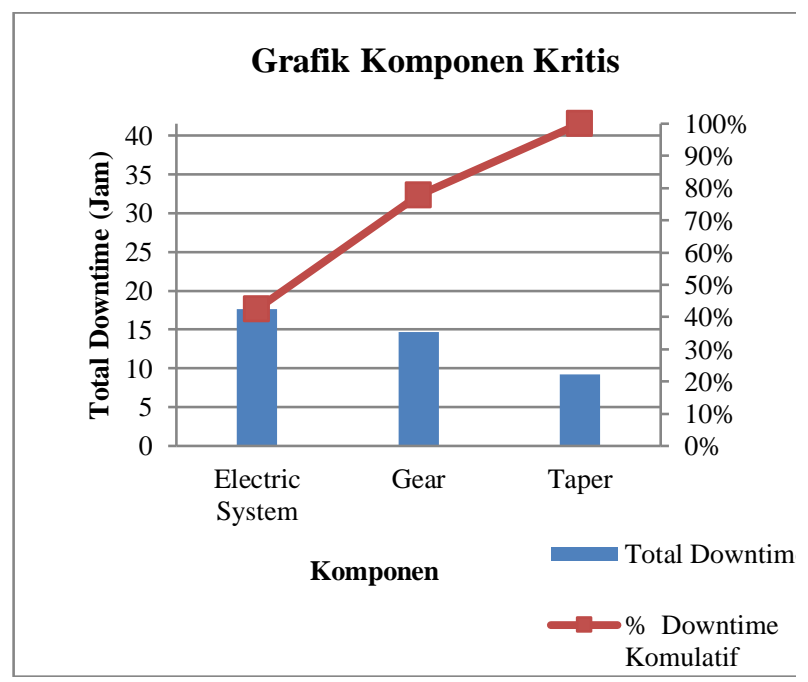

(Sumber Pengolahan Data, 2019)

Gambar 4.2 Diagram Pareto Downtime Mesin

Mesin No.3 dikategorikan sebagai mesin kritis dengan downtime terbesar dan dilihat dari persentase downtime komponen kritisnya adalah komponen Electric System (42,51\%) komponen Gear $(35,31 \%)$ dan komponen Taper (22,18\%).

Mesin No.3 diketahui selama kurun waktu 2 tahun mengalami 2 jenis kerusakan komponen, yaitu komponen electric system dan komponen gear, kedua komponen tersebut merupakan komponen kritis, namun komponen gear tidak dapat dihitung karena frekuensi kerusakannya hanya 1 (kurang dari 5).
Selanjutnya perhitungan hanya dilakukan pada komponen electric system dengan frekuensi kerusakan 8.

Downtime atau time to repair (TTR) adalah lama waktu perbaikan agar mesin dapat beroperasi kembali, sedangkan time to failure (TTF) merupakan interval selang waktu kerusakan antara saat terjadi kerusakan awal yang telah diperbaiki hingga kerusakan

\begin{tabular}{|c|c|c|c|c|}
\hline \multirow{2}{*}{$\begin{array}{c}\text { Nama } \\
\text { Komponen }\end{array}$} & \multicolumn{4}{|c|}{ Distribusi } \\
\cline { 2 - 5 } & $\begin{array}{c}\text { Ekspon } \\
\text { ensial }\end{array}$ & $\begin{array}{c}\text { Lognorm } \\
\text { al }\end{array}$ & Weibull & $\begin{array}{c}\text { Nor } \\
\text { mal }\end{array}$ \\
\hline $\begin{array}{c}\text { Electric } \\
\text { System }\end{array}$ & 0,995 & 0,995 & 1.000 & 0.974 \\
\hline
\end{tabular}

kembali terjadi.

Tabel 4.4 Hasil Perhitungan TTF dan TTR Komponen Electric System Mesin No.3

\begin{tabular}{|c|c|c|c|c|c|c|c|c|c|}
\hline$\dot{z}$ & 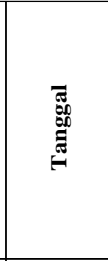 & 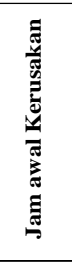 & 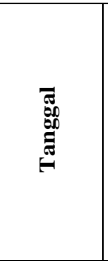 & 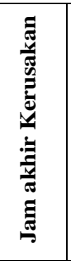 & 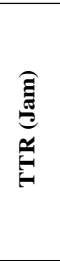 & \begin{tabular}{|c} 
Waktu \\
Akhir \\
Kerusak \\
an - \\
Waktu \\
Akhir \\
Rusak \\
(jam)
\end{tabular} & \begin{tabular}{|c|} 
Waktu \\
Awal \\
Kerusa \\
kan - \\
Waktu \\
Akhir \\
Rusak \\
(jam)
\end{tabular} & 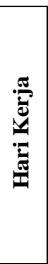 & $\underset{\mathrm{E}}{\stackrel{\mathrm{E}}{\mathrm{E}}}$ \\
\hline 1 & 11.01.17 & 16:10: & 11.01 .17 & $17: 00$ & 0.83 & & & & \\
\hline 2 & 22.09 .17 & 10:10 & 22.09 .17 & 11:20 & 1.17 & 0 & $2: 10$ & 172 & 1378.17 \\
\hline 3 & 17.11 .17 & $9: 40$ & 17.11 .17 & 10:25 & 0.75 & $4: 40$ & $1: 40$ & 41 & 333.83 \\
\hline 4 & 14.04 .18 & 10:54 & 14.04 .18 & $11: 58$ & 1.06 & $4: 35$ & $2: 54$ & 104 & 839.48 \\
\hline 5 & 16.07 .18 & $15: 26$ & \begin{tabular}{ll|}
17.07 .18 \\
\end{tabular} & 16:38 & 9.20 & 4:02 & $6: 26$ & 67 & 546.46 \\
\hline 6 & 08.08 .18 & 11:01 & 08.08 .18 & $11: 50$ & 0.82 & $0: 22$ & 3:01 & 19 & 155.38 \\
\hline
\end{tabular}

(Sumber Pengolahan Data, 2019)

\section{E. Validasi Pola Distribusi}

Pola distribusi yang sering digunakan untuk analisis keandalan dan laju kerusakan yaitu:

1. Distribusi Eksponensial

2. Distribusi Lognormal

3. Distribusi Weibull

4. Distribusi Normal

Menurut Ramadhan M. A. Z. (2018) Identifikasi distribusi kerusakan melalui 2 tahap yaitu Least Square Fitting Test dan Goodness of Fit Test. Least Square Fitting Test untuk menghitung nilai index of fit $(\mathrm{r})$.

Distribusi dengan nilai $\mathrm{r}$ terbesar dipilih untuk diuji dengan Goodness of Fit Test. Rumus umum yang terdapat dalam metode Least Square Fitting Test adalah:

$$
r=\frac{n \sum_{i=1}^{n} x i y i-\left(\sum_{i=1}^{n} x i\right)\left(\sum_{i=1}^{n} y i\right)}{\sqrt{\left[n \sum_{i=1}^{n} x i^{2}-\left(\sum_{i=1}^{n} x i\right)^{2}\right]\left[n \sum_{i=1}^{n} y i^{2}-\left(\sum_{i=1}^{n} y i\right)^{2}\right]}}(2)
$$


$b=\frac{n \sum_{i=1}^{n} x i y i-\left(\sum_{i=1}^{n} x i\right)\left(\sum_{i=1}^{n} y i\right)}{n \sum_{i=1}^{n} x i^{2}-\left(\sum_{i=1}^{n} x i\right)^{2}}$.

(Untuk distribusi Weibull, Normal dan Lognormal)

$b=\frac{n \sum_{i=1}^{n} x i y i-\left(\sum_{i=1}^{n} x i\right)\left(\sum_{i=1}^{n} y i\right)}{n \sum_{i=1}^{n} x i^{2}-\left(\sum_{i=1}^{n} x i\right)^{2}}$

(Untuk distribusi Eksponensial)

$a=\frac{\sum y i-b \cdot \sum x i}{n}$

Hasil perhitungan TTF dan TTR dapat berdistribusi tergantung dari jenis kerusakan yang terjadi, pola distribusi untuk dilakukan pengujian adalah yang memiliki nilai index of fit $(r)$ terbesar, untuk hasil perhitungan Time To Failure (TTF) ditunjukan pada Tabel 4.5.

Tabel 4.5. Hasil Perhitungan Index of Fit TTF

(Sumber Pengolahan Data, 2019)

Index of fit terbesar adalah distribusi Weibull dengan nilai $r=1,000$. Menurut Kurniawan (2013:57) Uji Goodness of Fit untuk distribusi Weibull menggunakan Uji Mann's Test, data benar berdistribusi Weibul jika $\mathrm{M}<\mathrm{F}_{\text {crit }}$ (Tabel F), untuk Uji statistik distribusi Weibull sebagai berikut:

$$
M=\frac{k_{1} \sum_{i=k 1+1}^{r-1}\left[\left(\ln t_{i+1}-\ln t_{i}\right) / M_{i}\right]}{k_{2} \sum_{i=1}^{k 1}\left[\left(\ln t_{i+1}-\ln t_{i}\right) / M_{i}\right]} .
$$

Dimana:

$$
\begin{aligned}
& k_{1}=\left[\frac{r}{2}\right] \text {. } \\
& k_{2}=\left[\frac{r-1}{2}\right] \text {. } \\
& M_{i}=Z_{i+1}-Z_{i} \\
& Z_{i}=\ln \left[-\ln \left(\frac{i-0,5}{n+0,25}\right)\right] \text {. }
\end{aligned}
$$

\begin{tabular}{|c|c|c|c|c|c|c|c|c|}
\hline $\mathbf{i}$ & ti & $\ln (\mathbf{t i})$ & $\mathbf{Z} \mathbf{i}$ & $\mathbf{M i}$ & $\begin{array}{c}\ln (\mathbf{t i + 1}+1)-\ln \\
\text { (ti) }\end{array}$ & $\begin{array}{c}(\operatorname{In}(\mathbf{t i}+1)-\mathbf{l n} \\
(\mathbf{t i})) / \mathbf{M i}\end{array}$ & $\mathbf{M}$ & Fcrit \\
\hline 1 & 155.38 & 5.05 & -2.302 & 1.213 & 0.721 & 0.594 & 3.99 & 6.39 \\
\hline 2 & 319.48 & 5.77 & -1.089 & 0.653 & 0.044 & 0.067 & & \\
\hline 3 & 333.83 & 5.81 & -0.436 & 0.530 & 1.161 & 2.191 & & \\
\hline 4 & 1066.28 & 6.97 & 0.094 & 0.572 & 0.257 & 0.449 & & \\
\hline 5 & 1378.17 & 7.23 & 0.666 & & & & & \\
\hline$\Sigma$ & 3253.1 & 30.82 & & & & & & \\
\hline $\mathrm{k} 1$ & 2 & & & & & & & \\
\hline $\mathrm{k} 2$ & 2 & & & & & & & \\
\hline
\end{tabular}

Tabel 4.6 Mann's Test Distribusi Weibull

(Sumber Pengolahan Data, 2019)

Nilai $M$ yang didapat lebih kecil dari $F_{\text {crit }}$. $3.99<6,39$ maka data berdistribusi Weibull.

Perhitungan parameter bentuk $(\beta)$ dan parameter skala $(\theta)$ distribusi Weibull adalah sebagai berikut:

$$
\begin{aligned}
& \beta=b \text {. } \\
& \theta=e^{-(a / b)} \\
& \beta=1,11 \\
& \theta=709,716 \text { jam }
\end{aligned}
$$

Hasil perhitungan Time To Repair (TTR) ditunjukan pada Tabel 4.7.

Tabel 4.7. Hasil Perhitungan Index of Fit TTR

\begin{tabular}{|c|c|c|c|c|}
\hline \multirow{2}{*}{$\begin{array}{c}\text { Nama } \\
\text { Kompon } \\
\text { en }\end{array}$} & \multicolumn{4}{|c|}{ Distribusi } \\
\cline { 2 - 5 } & $\begin{array}{c}\text { Ekspone } \\
\text { nsial }\end{array}$ & $\begin{array}{c}\text { Logno } \\
\text { rmal }\end{array}$ & $\begin{array}{c}\text { Weibul } \\
\text { I }\end{array}$ & $\begin{array}{c}\text { Norm } \\
\text { al }\end{array}$ \\
\hline $\begin{array}{c}\text { Electric } \\
\text { System }\end{array}$ & 0,858 & 0,797 & 0,718 & 0,718 \\
\hline
\end{tabular}

(Sumber Pengolahan Data, 2019)

Index of fit terbesar yaitu distribusi Eksponensial dengan nilai $\mathrm{r}=0,858$. Menurut Maulana et. al. (2017) Uji Goodness of Fit untuk Distribusi Eksponensial menggunakan Uji Barlett Test, data benar berdistribusi

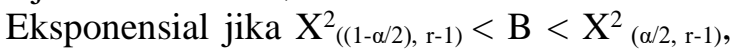
$\alpha / 2, \mathrm{r}-1$ dilihat pada tabel chi square, untuk Uji statistik distribusi Uji statistik distribusi Eksponensial adalah sebagai berikut:

$$
B=\frac{2 r\left[\ln \left(\left(\frac{1}{r}\right) \sum_{u}^{r} t i\right)-\left(\frac{1}{r}\right) \sum_{i=1}^{r} \ln t i\right]}{1+\frac{(r+1)}{6 r}} .
$$

Dimana:

$$
\begin{aligned}
t i & =\text { Waktu kerusakan ke } \mathrm{i} . \\
r & =\text { Jumlah kerusakan. } \\
B & =\text { Nilai uji statistik Barlett Test } .
\end{aligned}
$$

$$
\begin{aligned}
& B=\frac{2 \times 6\left[\ln \left(\left(\frac{1}{6}\right) 12,71\right)-\left(\frac{1}{6}\right) 0,34\right]}{1+\frac{(6+1)}{6 x 6}}=6,97 \\
& X^{2}{ }_{((1-\alpha / 2), r-1)}=0,83 \\
& X_{(\alpha / 2, r-1)}=12.83
\end{aligned}
$$

Karena nilai perhitungan $\mathrm{B}$ lebih besar dari $\mathrm{X}_{(1-\alpha) / 2, \mathrm{r}-1}$ dan lebih kecil dari $\mathrm{X}_{\alpha / 2, \mathrm{r}-1}^{2}$ maka data berdistribusi Eksponensial.

Perhitungan parameter $\lambda$ pada distribusi Eksponensial adalah sebagai berikut:

$$
\begin{aligned}
& \lambda=b . . . . . . . . . . . \\
& \lambda=0.26 \mathrm{jam} .
\end{aligned}
$$

\section{F. Perhitungan MTTF dan MTTR}

Menurut Kurniawan (2013:58) perhitungan Mean Time To Failure (MTTF) dan perhitungan Mean Time To Repair (MTTR) pada komponen electric system sesuai dengan distribusi yang telah didapat menggunakan rumus sebagai berikut:

MTTF untuk distribusi Weibull:

$$
M T T F=\theta . \Gamma\left(1+\frac{1}{\beta}\right) \text {. }
$$


Dimana:

$$
\begin{aligned}
& \Gamma=\text { Tabel fungsi Gamma } \\
& \text { MTTF }=e\left[\left(-\left(\frac{503}{709,716}\right)^{1,11}\right)\right]=682,58 \mathrm{jam}
\end{aligned}
$$

MTTR untuk distribusi Eksponensial:

$$
\operatorname{MTTR}=\frac{1}{\lambda}
$$

$$
\operatorname{MTTR}=\frac{1}{0,26}=3,84 \mathrm{jam}
$$

Perhitungan keandalan dilakukan untuk mengetahui probabilitas kinerja dari sistem/alat untuk memenuhi fungsi yang diharapkan. Menurut Mulia (2017) rumus keandalan distribusi Weibull adalah:

$$
R(t)=e\left(-\left(\frac{t}{\theta}\right)^{\beta}\right)
$$

Dimana:

$$
\begin{aligned}
e & =2,71828 . \\
t & =\text { Banyaknya hari kerja } \\
\beta & =\text { Parameter bentuk. } \\
\theta & =\text { Parameter skala. }
\end{aligned}
$$

Hasil perhitungan keandalan distribusi Weibull:

$$
R(t)=e\left[\left(-\left(\frac{503}{709,716}\right)^{1,11}\right)\right]=0,5066
$$

Dari hasil perhitungan didapat Reliability komponen Electric System dengan $\mathrm{t}=503$ hari adalah 0,5066 atau sebesar 50,66\%.

\section{G. Perhitungan Interval Perawatan}

Menurut Ramadhan M. A. Z. (2018) untuk menentukan interval waktu pemeriksaan komponen berdasarkan waktu produksi yang ada dilakukan tahap-tahap berikut:

1. Rata-Rata Jam Kerja Perbulan:

Hari kerja selama 2 tahun $=525$ hari

Rata-rata hari kerja per bulan $=525 / 24=$ $21,88 \approx 22$ hari/bulan.

Jam kerja setiap hari $=8$ jam/hari.

Rata-Rata Jam Kerja Per Bulan $=22 \times 8=$ $176 \mathrm{jam} / \mathrm{bulan}$.

2. Jumlah Kerusakan

Jumlah kerusakan selama penelitian

Jumlah kerusakan selama 2 tahun $=6$ kali

3. Waktu Rata-Rata Yang Dibutuhkan Untuk Perbaikan Perbaikan $(1 / \mu)$

$$
\begin{aligned}
& \frac{1}{\mu}=\frac{M T T R}{\text { rata-rat jam kerja per bulan }} \text {. } \\
& \mu=\frac{1}{1 / \mu} \text {. }
\end{aligned}
$$

$$
\begin{aligned}
& \frac{1}{\mu}=\frac{3,84}{176}=0.021 \\
& \mu=\frac{1}{0.021}=47.62
\end{aligned}
$$

4. Waktu Rata-rata Melakukan Pemeriksaan $(1 / \mathrm{i})$

Rata-rata 1 kali pemeriksaan $=\Sigma \mathrm{t}_{\mathrm{i}} /$ jumlah kerusakan

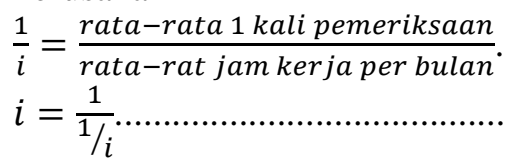

Rata-rata 1 kali pemeriksaan $=12.71 / 6=$ 2,118 jam

$$
\begin{gathered}
\frac{1}{i}=\frac{2,118}{176}=0,011 \\
i=\frac{1}{0,011}=90,90
\end{gathered}
$$

5. Rata-Rata Kerusakan

$$
\begin{aligned}
& k=\frac{\text { jumlah kerusakan }}{24 \text { bulan }} \\
& k=\frac{6}{24}=0,25 \text { kerusakan } / \text { bulan }
\end{aligned}
$$

6. Frekuensi Pemeriksaan Optimal

$$
\begin{aligned}
& n=\sqrt{\frac{k \cdot i}{\mu}} \\
& n=\sqrt{\frac{0.25 \times 90.90}{47.46}}=0,690 \mathrm{jam}
\end{aligned}
$$

7. Interval Waktu Pemeriksaan

$$
\begin{aligned}
& t_{i}=\frac{\text { rata-rata jam kerja per bulan }}{n} \\
& t_{i}=\frac{176}{0,690}=255.07 \mathrm{jam}=32 \mathrm{hari}
\end{aligned}
$$

8. Perhitungan Nilai Downtime

$$
\begin{aligned}
& D_{(n)}=\frac{k}{\mu \cdot n}+\frac{1}{i} \\
& D_{(n)}=\frac{0,25}{47.62 \times 0,690}+\frac{1}{90.90}=0,0186 \\
& =1,86 \%
\end{aligned}
$$

9. Perhitungan Availability

$$
\begin{aligned}
& A_{(t p)}=\left(1-D_{(t p)}\right) \times 100 \% \ldots \ldots \ldots \ldots \ldots . .(32) \\
& A_{(t p)}=(1-0.0186) \times 100 \%=98.14 \%
\end{aligned}
$$

\section{H. Hasil Pembahasan}

Tindakan perawatan yang disarankan dan interval perawatan yang perlu dilakukan pada komponen Electric System yang sering rusak dapat dilihat pada Tabel 4.8. 
Tabel 4.8 Kegiatan Perawatan dan Interval Perawatan yang Diusulkan

\begin{tabular}{|c|c|c|c|c|c|}
\hline $\begin{array}{l}\text { ID / } \\
\text { Nama } \\
\text { Mesin }\end{array}$ & $\begin{array}{l}\text { Kom- } \\
\text { ponen } \\
\text { Kritis }\end{array}$ & $\begin{array}{c}\text { Jenis } \\
\text { Kegagalan }\end{array}$ & IDT & $\begin{array}{c}\text { Mainte- } \\
\text { nance } \\
\text { Task }\end{array}$ & $\begin{array}{c}\text { Inter- } \\
\text { val Pe- } \\
\text { rawat- } \\
\text { an } \\
\text { (Jam) }\end{array}$ \\
\hline \multirow{5}{*}{ 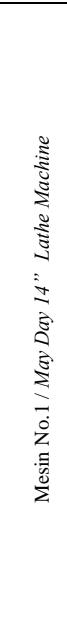 } & \multirow{5}{*}{ 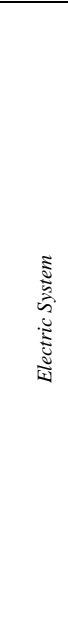 } & $\begin{array}{l}\text { Kontaktor } \\
\text { rusak }\end{array}$ & $\begin{array}{l}\text { Dampak tidak } \\
\text { langsung, } \\
\text { tersembunyi dan } \\
\text { berpengaruh } \\
\text { terhadap produksi }\end{array}$ & $\begin{array}{l}\text { No Task } \\
\text { (CM } \\
\text { only) }\end{array}$ & \multirow{5}{*}{255.07} \\
\hline & & Relay rusak & $\begin{array}{l}\text { Dampak tidak } \\
\text { langsung, } \\
\text { tersembunyi dan } \\
\text { berpengaruh } \\
\text { terhadap produksi }\end{array}$ & $\begin{array}{l}\text { No Task } \\
\text { (CM } \\
\text { only) }\end{array}$ & \\
\hline & & $\begin{array}{l}\text { Kabel } \\
\text { terkelupas }\end{array}$ & $\begin{array}{l}\text { Dampak tidak } \\
\text { langsung, } \\
\text { tersembunyi dan } \\
\text { berpengaruh } \\
\text { terhadap } \\
\text { keselamatan }\end{array}$ & $\begin{array}{l}\text { Condi- } \\
\text { tion } \\
\text { Monitor } \\
\text {-ing }\end{array}$ & \\
\hline & & Kabel putus & $\begin{array}{l}\text { Dampak tidak } \\
\text { langsung, } \\
\text { tersembunyi dan } \\
\text { berpengaruh } \\
\text { terhadap produksi }\end{array}$ & $\begin{array}{l}\text { No Task } \\
\text { (CM } \\
\text { only) }\end{array}$ & \\
\hline & & $\begin{array}{l}\text { Kumparan } \\
\text { stopper } \\
\text { break }\end{array}$ & $\begin{array}{l}\text { Dampak tidak } \\
\text { langsung, } \\
\text { tersembunyi dan } \\
\text { berpengaruh } \\
\text { terhadap produksi }\end{array}$ & $\begin{array}{l}\text { Peng- } \\
\text { gantian } \\
\text { Terjad- } \\
\text { wal }\end{array}$ & \\
\hline
\end{tabular}

(Sumber Pengolahan Data, 2019)

Pada komponen Electric System dengan interval waktu perawatan 255.07 jam atau 32 hari kerja perlu tindakan Condition Monitoring guna mengurangi gangguan produksi, untuk unpredictable failure dilakukan Corrective Maintenance dan untuk kegagalan karena usia komponen dilakukan penggantian terjadwal.

\section{KESIMPULAN}

\section{A. Kesimpulan}

Berdasarkan analisis data didapatkan kesimpul sebagai berikut:

1. Untuk menentukan tindakan perawatan yang optimal pada Mesin Bubut CYL1640G berdasarkan Reliability Centered Maintenance (RCM) dengan membuat hirarki fungsi sistem dan analisis fungsi sistem serta kegagalan sistem, selanjutnya melakukan analisis Failure Modes and Effect Analyze (FMEA) diperoleh 3 komponen kritis dengan nilai RPN tertinggi yaitu komponen Electric System dengan RPN 196 (33.22\%), Shaft dengan RPN 119 (20.17\%) dan Gear dengan RPN 72 $(12.20 \%)$. Kemudian dilakukan analisa Intermediate Decision Tree (IDT) mengetahui moda kegagalan apakah termasuk yang tampak atau tersembunyi, dari hasil IDT dilanjutkan dengan Logic Tree Analysis (LTA) untuk menentukan tugas pemeliharaan yang optimal, kemudian dilakukan analisis keandalan untuk menghitung TTF, TTR, MTTF dan MTTR untuk mendapatkan interval perawatan. Dan dari hasil analisis keandalan dapat dilihat dalam grafik komponen kritis terdapat 3 komponen kritis dengan persentase kerusakan yaitu komponen Electric System 42,51\%, Gear 35,31\%, dan Taper 22,18\%.

2. Hasil analisis interval waktu perawatan berdasarkan metode Reliability Centered Maintenance (RCM) untuk komponen yang memiliki kegagalan potensial adalah komponen Electric System, dengan breakdown sebanyak 6 kali dalam 2 tahun. Hasil yang didapat berupa pemecahan masalah yaitu dilakukan interval perawatan pada komponen Electric System dengan interval waktu perawatan 255.07 jam atau 32 hari kerja.

\section{B. Saran}

Adapun beberapa saran yang diberikan kepada perusahaan adalah:

1. Pihak perusahaan diharapkan mendata atau mengakses secara lengkap seluruh kerusakan yang terjadi pada mesin bubut CY-L1640G yang ada sehingga dapat dibuatkan program tentang keandalan, jadwal perawatan, penggantian komponen, dan persediaan dengan tepat.

2. Untuk komponen yang masih mengalami breakdown maintenance, diharapkan agar melakukan tindakan perawatan pencegahan secara intensif untuk menghindari terjadinya kerusakan yang dapat mempengaruhi berhentinya proses produksi.

3. Melakukan autonomous maintenance oleh operator produksi, checksheet harian mesin diisi oleh tiap operator sehingga tim maintenance dapat mengontrol dan mengevaluasi kondisi mesin

\section{DAFTAR PUSTAKA}

Ansori, Nachnul dan Mustajib, M. Imron (2013). Sistem Perawatan Terpadu, Yogyakarta: Graha Ilmu.

Aufar, A. N., Leksananto, K., dan Prasetiyo, H. (2014). Usulan Kebijakan Perawatan Area Produksi Trim Chassis Dengan Menggunakan Metode Reliability Centered Maintenance (Studi Kasus: PT. Nissan Motor Indonesia). REKA INTEGRA, 2(4). 
Heizer J. dan Render B. (2015). Manajemen Operasi: Manajemen Keberlangsungan dan Rantai Pasokan. Edisi 11. Jakarta. Salemba Empat.

Kirana, U. T., Alhilman, J., dan Sutrisno, S. (2015). Perencanaan Kebijakan Perawatan Mesin Corazza FF100 Pada Line 3 PT. XYZ Dengan Metode Reliability Centered Maintenance (RCM) II. eProceedings of Engineering, 2(2).

Kurniawati, D. A., \& Muzaki, M. L. (2017). Analisis Perawatan Mesin Dengan Pendekatan RCM Dan MVSM. Jurnal Optimasi Sistem Industri, 16(2), 89-105.

Kurniawan, Fajar. (2013). Teknik dan Aplikasi Manajemen Perawatan Industri. Edisi Pertama. Yogyakarta: Graha Ilmu.

Maulana, E., Ilhami, M. A., \& Kurniawan, B. (2017). Usulan Perencanaan Perawatan Mesin Coldsaw Dengan Metode Reliability Centered Maintenance Dan Reliability Block Diagram (Study Kasus: PT. Krakatau Wajatama). Jurnal Teknik Industri Untirta.

Pamungkas, A. Y. (2016). Analisis Perawatan Mesin Produksi Dengan Menggunakan MEtode Reliability Centered Maintenance (RCM) Di Perusahaan Konveksi Ratna. S1 Teknik Industri, Universitas Islam Negri Sunan Kalijaga. Yogyakarta.

Pranoto, Hadi. (2015). Reliability Centered Maintenance (RCM). Jakarta: Mitra Wacana Media.

Ramadhan, M. A. Z. (2018). Penentuan Interval Waktu Preventive Maintenance Pada Nail Making Machine Dengan Menggunakan Metode Reliability Centered Maintenance (RCM) II (Studi Kasus: PT. Surabaya Wire). (Doctoral dissertation, Universitas Muhammadiyah Sidoarjo).

Siswanti, E. (2017). Perencanaan Penjadwalan Dan Persediaan Sparepart Dengan Metode Reliability Centered
Maintenance (RCM) DI PT. X. Teknik Industri, 6(1). 